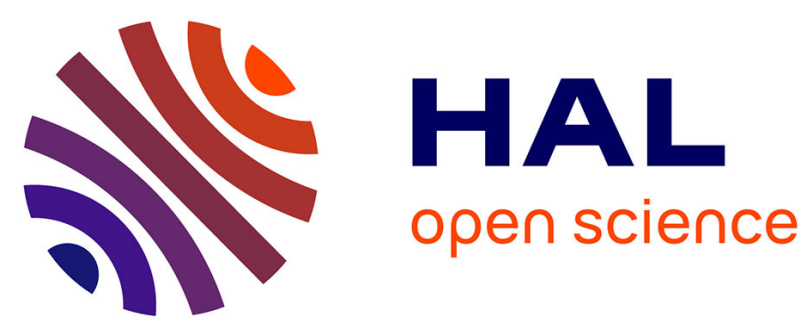

\title{
CARBON DIOXIDE INFLUENCE ON THE THERMAL FORMATION OF COMPLEX ORGANIC MOLECULES IN INTERSTELLAR ICE ANALOGS
}

Vassilissa Vinogradoff, Fabrice Duvernay, Nicolas Fray, Michaelle Bouilloud, Thierry Chiavassa, Hervé Cottin

\section{To cite this version:}

Vassilissa Vinogradoff, Fabrice Duvernay, Nicolas Fray, Michaelle Bouilloud, Thierry Chiavassa, et al.. CARBON DIOXIDE INFLUENCE ON THE THERMAL FORMATION OF COMPLEX ORGANIC MOLECULES IN INTERSTELLAR ICE ANALOGS. The Astrophysical journal letters, 2015, 10.1088/2041-8205/809/2/L18 . hal-01208166

\section{HAL Id: hal-01208166 https://hal.science/hal-01208166}

Submitted on 26 Jan 2017

HAL is a multi-disciplinary open access archive for the deposit and dissemination of scientific research documents, whether they are published or not. The documents may come from teaching and research institutions in France or abroad, or from public or private research centers.
L'archive ouverte pluridisciplinaire HAL, est destinée au dépôt et à la diffusion de documents scientifiques de niveau recherche, publiés ou non, émanant des établissements d'enseignement et de recherche français ou étrangers, des laboratoires publics ou privés. 


\title{
CARBON DIOXIDE INFLUENCE ON THE THERMAL FORMATION OF COMPLEX ORGANIC MOLECULES IN INTERSTELLAR ICE ANALOGS
}

\author{
V. VinogradofF ${ }^{1,3}$, F. Duvernay ${ }^{2}$, N. Fray $^{1}$, M. Bouilloud ${ }^{1}$, T. Chiavassa ${ }^{2}$, and H. Cottin ${ }^{1}$ \\ ${ }^{1}$ LISA Laboratoire Interuniversitaire des Systèmes Atmosphériques, UMR CNRS 7583, Université Paris Est Créteil (UPEC), \\ Université Paris Diderot (UPD), Institut Pierre Simon Laplace, Labex ESEP, Paris, France \\ ${ }^{2}$ PIIM, Laboratoire de Physique des Interactions Ioniques et Moléculaires, Université Aix-Marseille, UMR CNRS 7345, Marseille, France \\ 3 IMPMC, Institut de Minéralogie, de Physique des Matériaux et de Cosmochimie, UMR CNRS 7590, Sorbonne Universités, \\ UPMC, IRD UMR 206, Muséum National d'Histoire Naturelle, Paris, France; vvinogradoff@mnhn.fr \\ Received 2015 June 22; accepted 2015 July 10; published 2015 August 13
}

\begin{abstract}
Interstellar ices are submitted to energetic processes (thermal, UV, and cosmic-ray radiations) producing complex organic molecules. Laboratory experiments aim to reproduce the evolution of interstellar ices to better understand the chemical changes leading to the reaction, formation, and desorption of molecules. In this context, the thermal evolution of an interstellar ice analogue composed of water, carbon dioxide, ammonia, and formaldehyde is investigated. The ice evolution during the warming has been monitored by IR spectroscopy. The formation of hexamethylenetetramine (HMT) and polymethylenimine (PMI) are observed in the organic refractory residue left after ice sublimation. A better understanding of this result is realized with the study of another ice mixture containing methylenimine (a precursor of HMT) with carbon dioxide and ammonia. It appears that carbamic acid, a reaction product of carbon dioxide and ammonia, plays the role of catalyst, allowing the reactions toward HMT and PMI formation. This is the first time that such complex organic molecules (HMT, PMI) are produced from the warming (without VUV photolysis or irradiation with energetic particles) of abundant molecules observed in interstellar ices $\left(\mathrm{H}_{2} \mathrm{O}, \mathrm{NH}_{3}, \mathrm{CO}_{2}, \mathrm{H}_{2} \mathrm{CO}\right)$. This result strengthens the importance of thermal reactions in the ices' evolution. HMT and PMI, likely components of interstellar ices, should be searched for in the pristine objects of our solar system, such as comets and carbonaceous chondrites.
\end{abstract}

Key words: astrochemistry - comets: general - ISM: molecules - methods: laboratory: solid state molecular processes - solid state: refractory

\section{INTRODUCTION}

Interstellar grains play an important role in the interstellar medium (ISM). On the one hand, they allow chemical reactions that could not happen in gas phase (such as the formation of $\mathrm{H}_{2}$; Gould et al. 1963). On the other hand, due to low temperatures, they accumulate matter, around a silicate or carbonaceous core, forming an ice mantle. There, chemical reactions can occur as a result of energetic processes and form complex organic molecules (defined as bearing more than six atoms (Herbst \& Van Dishoeck 2009). The pristine ice is mainly composed of water, carbon monoxide, carbon dioxide, methanol, ammonia, and formaldehyde (Gibb et al. 2004; Boogert et al. 2008; Öberg et al. 2011). From the evolution of molecular cloud to planetary system, icy grains can be submitted to energetic processes such as UV photolysis, irradiation by energetic particles, and heating. All of the processes will affect and change the ice composition, leading to an evolved grain.

Many of the organic molecules detected in the gas phase could have been initially formed in the ice mantle before being released to the gas phase by desorption (Herbst \& Van Dishoeck 2009). The most refractory component of the organic material should, however, remain in the solid phase of the grain. They are difficult to detect due to the remotesensing spectroscopic techniques. Some of the molecules resulting from the chemistry of ices could have been incorporated into the matter of comets and asteroids during our planetary system formations. Their study is therefore important for the origin matter understanding of the solar system.

Laboratory simulations of the ice evolution, from ISM to planetary systems, are investigating the chemical and physical changes undergone by the ices. Photolysis at low temperatures is an important energetic process that produces molecules (Öberg et al. 2009). Recent studies have shown the importance of thermal reactions involving the whole ice mantle and forming complex organic molecules from 20 to $400 \mathrm{~K}$ (Theulé et al. 2013 and references therein). An organic refractory matter at room temperature, called residue, is usually obtained from these experiments where interstellar ice analogs are photolyzed and warmed. A small fraction of the refractory species can reach high molecular masses, up to $4000 \mathrm{amu}$ (Danger et al. 2013). This refractory matter could be similar to a part of the cometary and asteroidal matter.

Among the molecules detected in situ by IR spectroscopy in these organic residues, hexamethylenetetramine (HMT; $\mathrm{C}_{6} \mathrm{H}_{12} \mathrm{~N}_{4}$ ) can reach up to $50 \%$ of residue mass (Bernstein et al. 1995; Cottin et al. 2001; Muñoz Caro \& Schutte 2003; Muñoz Caro et al. 2004). This molecule is of prime interest since it is a source of $\mathrm{C}-\mathrm{N}$ bonds, but also because its acid hydrolysis forms ammonia, formaldehyde, and likely some amino acids (Wolman et al. 1971). The HMT formation mechanism in interstellar ices, determined from laboratory studies, is shown in Equation (1). The initial ice mixture is made of $\mathrm{H}_{2} \mathrm{O}: \mathrm{CH}_{3} \mathrm{OH}: \mathrm{NH}_{3}$ and is photolyzed at low temperatures and then warmed ( $h \nu$ :UV photolysis; $\Delta$ :heating; Vinogradoff et al. 2013). HMT appears to be the product of a 
complex suite of thermal reactions involving ammonia and formaldehyde, but also the formic acid as an inevitable catalyst (Vinogradoff et al. 2012). As far as we know, formic acid is only produced by an irradiation process in interstellar ice (unlike the formaldehyde) through a mechanism such as the photolysis of methanol in a water environment (Öberg et al. 2009; Vinogradoff et al. 2013) or by irradiation with energetic electrons on $\mathrm{H}_{2} \mathrm{O}$ :CO ice mixtures (Bennett et al. 2011). The first intermediate in the HMT formation is the aminomethanol, from the thermal reaction of $\mathrm{H}_{2} \mathrm{CO}$ and $\mathrm{NH}_{3}$ (Bossa et al. 2009; Duvernay et al. 2014; $\mathrm{NH}_{3} / \mathrm{H}_{2} \mathrm{CO}>1$ ), then a succession of reactions and intermediates activated by $\mathrm{HCOOH}$ leads to HMT. In addition to HMT, a co-product of the reaction has been identified, the polymethylenimine (PMI; Vinogradoff et al. 2012). The structure of the PMI polymer is not yet fully understood but is suspected to be chains of $-\left(\mathrm{CH}_{2}-\mathrm{NH}\right)_{n^{-}}$ (Danger et al. 2011; Vinogradoff et al. 2012). Hence, HMT can be seen as an indicator of thermal processes undergone by an ice.

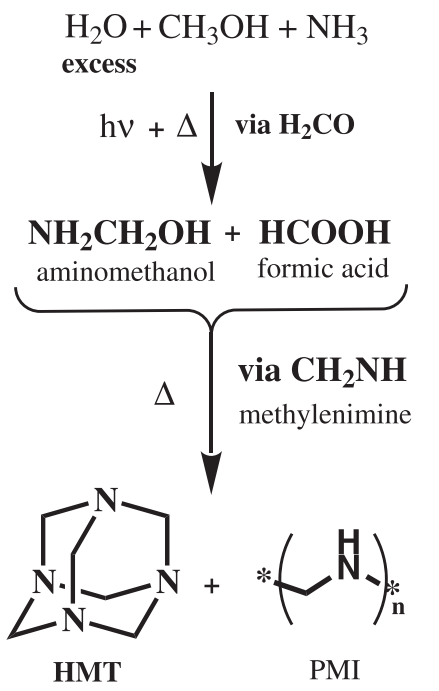

major product

In this study, we present for the first time a simple, realistic, and straightforward scenario of HMT and PMI production based solely on the thermal processes of an interstellar ice analog made only of abundant molecules observed in interstellar ices: water $\left(\mathrm{H}_{2} \mathrm{O}\right)$, ammonia $\left(\mathrm{NH}_{3}\right)$, carbon dioxide $\left(\mathrm{CO}_{2}\right)$, and formaldehyde $\left(\mathrm{H}_{2} \mathrm{CO}\right.$; Gibb et al. 2004). Thermal reactions between the reactants taken two by two are known in the literature: $\mathrm{NH}_{3}+\mathrm{H}_{2} \mathrm{CO} \rightarrow \mathrm{NH}_{2} \mathrm{CH}_{2} \mathrm{OH}$ (aminomethanol; Bossa et al. 2009), $\mathrm{CO}_{2}+\mathrm{NH}_{3} \rightarrow \mathrm{NH}_{2} \mathrm{COO}^{-} \mathrm{NH}_{4}^{+}$(ammonium carbamate) $+\mathrm{NH}_{2} \mathrm{COOH}$ (carbamic acid; Bossa et al. 2008; Lv et al. 2014; Noble et al. 2014; Rodríguez-Lazcano et al. 2014). However, the thermal reactivity of all reactants and products together from 25 to $300 \mathrm{~K}$ were not known. Although no photolysis step is involved in our experiments, we report that an organic residue containing HMT and PMI is formed. We investigated a second ice mixture from the penultimate precursor of $\mathrm{HMT}$, the methyleneimine $\mathrm{CH}_{2} \mathrm{NH}$, with $\mathrm{CO}_{2}$ and $\mathrm{NH}_{3}$, in support of an emerging hypothesis on HMT and PMI formation from such ice mixtures.

This new chemical mechanism in ice mixtures has astrophysical implications regarding the formation of HMT and PMI in interstellar grains and their detections in pristine

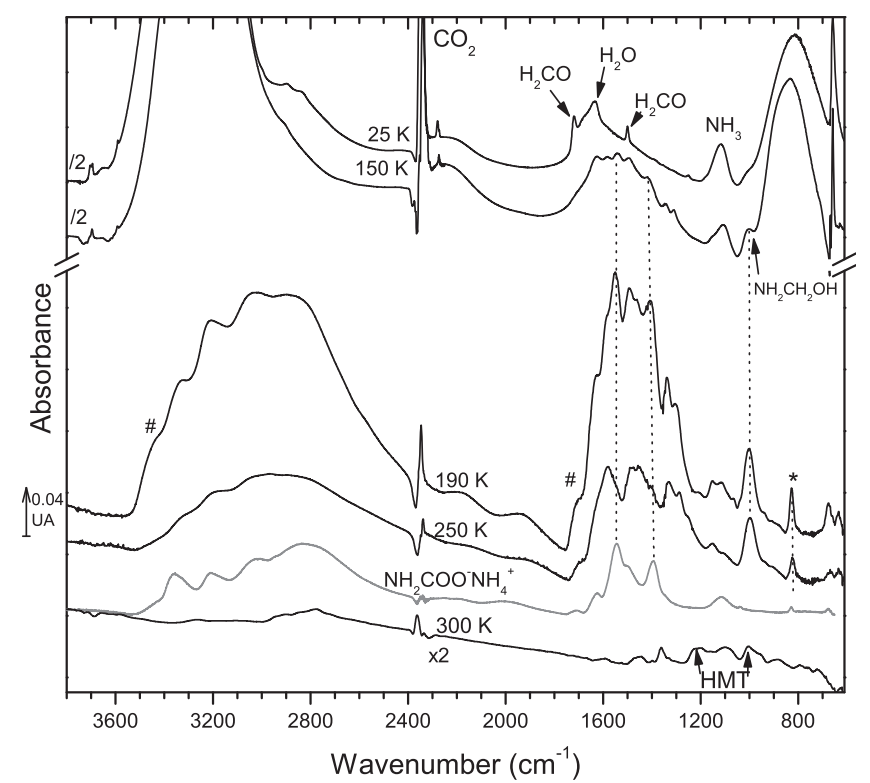

Figure 1. IR spectra of the ice $\mathrm{H}_{2} \mathrm{O}: \mathrm{NH}_{3}: \mathrm{CO}_{2}: \mathrm{H}_{2} \mathrm{CO} 10: 1: 1: 0.3$ at 25, 150, 190,250 , and $300 \mathrm{~K}$. The IR spectra at 150,190 , and $250 \mathrm{~K}$ can be compared to the IR spectrum of $\mathrm{NH}_{2} \mathrm{COO}-\mathrm{NH}_{4}^{+}$(at $240 \mathrm{~K}$; Bossa et al. 2008; the star marks the band at $829 \mathrm{~cm}^{-1}$ ). The hashes show the bands attributed to $\mathrm{NH}_{2} \mathrm{COOH}$.

solar system bodies, such as by the Rosetta mission, currently in orbit around the comet $67 \mathrm{P} /$ Churyumov-Gerasimenko.

\section{METHOD: EXPERIMENTAL SETUPS}

Ices are condensed from gaseous mixtures made of $\mathrm{H}_{2} \mathrm{O}$ triply distilled, $\mathrm{NH}_{3}$ (Air Liquide, 99.995\%), $\mathrm{CO}_{2}$ (Air Liquide, $99.9 \%$ ), and $\mathrm{H}_{2} \mathrm{CO}$, produced from the heating paraformaldehyde (Aldrich). Methylenimine $\left(\mathrm{CH}_{2} \mathrm{NH}\right)$ was prepared according to Guillemin \& Denis (1988) protocol and kept in liquid nitrogen for storage. Due to its degradation and fast polymerization, $\mathrm{CH}_{2} \mathrm{NH}$ has to be quickly injected and cooled on the sample holder at $80 \mathrm{~K}$. The reactants were prepared at room temperature and split into two vacuum mixing lines, leading to a double injection in the vacuum chamber and thereby avoiding reaction in the gas phase.

The experimental setup OREGOC at LISA (Créteil, France) was used for the $\mathrm{H}_{2} \mathrm{O}: \mathrm{NH}_{3}: \mathrm{CO}_{2}: \mathrm{H}_{2} \mathrm{CO}$ experiment (Vinogradoff et al. 2013). For the $\mathrm{CH}_{2} \mathrm{NH}: \mathrm{NH}_{3}: \mathrm{CO}_{2}$ ice mixture, and due to the unstable molecule $\mathrm{CH}_{2} \mathrm{NH}$, the experimental setup RING at PIIM (Marseille, France) was used (Vinogradoff et al. 2012). Both devices contain a support cooled down to a temperature lower than $25 \mathrm{~K}$ due to a closed-cycle helium cryostat (Advanced Research Systems, Inc.). The temperature is adjustable with a resistive heater, on the support holder, and driven by a temperature controller (Lakeshore). This support is inside a high-vacuum stainless steel chamber evacuated at about $10^{-8}$ mbar. For direct in situ analysis, we used an FTIR spectrometer, and spectra were recorded between 4000 and $650 \mathrm{~cm}^{-1}$ (resolution: $1 \mathrm{~cm}^{-1}, 100$ scans). All parameters of the two devices can be found in Vinogradoff et al. $(2012,2013)$. The mixing ratios of the mixture were derived from standard manometric techniques and from the IR spectra to estimate the column density of the components according to their band strengths, for $\mathrm{NH}_{3}: 1.63$ $10^{-17} \mathrm{~cm}$ molecule ${ }^{-1}$ at $1100 \mathrm{~cm}^{-1} ; 2.310^{-17} \mathrm{~cm}$ molecule ${ }^{-1}$ at 
Table 1

Attributions and Attempt Assignments for the Bands Observed on the IR Spectrum at 250 and $300 \mathrm{~K}$ in the Experiment Starting with $\mathrm{H}_{2} \mathrm{O}: \mathrm{NH}_{3}: \mathrm{CO}_{2}: \mathrm{H}_{2} \mathrm{CO}$ at $250 \mathrm{~K}$ (Figure 1) ${ }^{\mathrm{a}}$

\begin{tabular}{|c|c|c|c|c|c|}
\hline $\begin{array}{l}\bar{\nu} \\
\left(\mathrm{cm}^{-1}\right)\end{array}$ & Vibration & Assignment & Molecule & $\bar{\nu}\left(\mathrm{cm}^{-1}\right)$ & Vibration \\
\hline $3330 \mathrm{~b}$ & $\nu\left(\mathrm{NH}_{2}\right)$ & $\mathrm{NH}_{2} \mathrm{COO}^{-} \mathrm{NH}_{4}^{+}$ & HMT & 2952 & $\nu_{\mathrm{as}}\left(\mathrm{CH}_{2}\right)$ \\
\hline $3210 \mathrm{~b}$ & $\nu\left(\mathrm{NH}_{2}\right)$ & $\mathrm{NH}_{4}^{+}$ & HMT & 2921 & $\nu\left(\mathrm{CH}_{2}\right)$ \\
\hline $3030 \mathrm{~b}$ & $\nu\left(\mathrm{NH}_{2}\right)$ & $\mathrm{NH}_{4}^{+}$ & HMT & 2873 & $\nu_{\mathrm{s}}\left(\mathrm{CH}_{2}\right)$ \\
\hline 1690 & $\nu(\mathrm{C}=\mathrm{O})$ & $\mathrm{NH}_{2} \mathrm{COOH}$ & HMT & 1458 & $\omega\left(\mathrm{CH}_{2}\right)$ \\
\hline 1627 & $\delta\left(\mathrm{NH}_{2}\right)$ & $\mathrm{NH}_{2} \mathrm{COO}^{-} \mathrm{NH}_{4}^{+}$ & HMT & 1370 & $\delta\left(\mathrm{CH}_{2}\right)$ \\
\hline 1576 & $\nu\left(\mathrm{COO}^{-}\right) ?$ & not attributed & HMT & 1238 & $\nu(\mathrm{CN})$ \\
\hline 1549 & $\nu_{\mathrm{as}}\left(\mathrm{COO}^{-}\right)$ & $\mathrm{NH}_{2} \mathrm{COO}^{-} \mathrm{NH}_{4}^{+}$ & HMT & 1004 & $\nu(\mathrm{CN})$ \\
\hline 1493 & $\delta\left(\mathrm{NH}_{4}^{+}\right)$ & $\mathrm{NH}_{2} \mathrm{COO}^{-} \mathrm{NH}_{4}^{+}$ & HMT & 812 & $\rho_{\mathrm{s}}\left(\mathrm{CH}_{2}\right)$ \\
\hline 1458 & $\ldots$ & not attributed & PMI & 2780 & $\nu_{\mathrm{s}}\left(\mathrm{CH}_{2}\right)$ \\
\hline 1403 & $\nu_{\mathrm{s}}\left(\mathrm{COO}^{-}\right)$ & $\mathrm{NH}_{2} \mathrm{COO}^{-} \mathrm{NH}_{4}^{+}$ & PMI & $1453 \mathrm{~b}$ & $\delta\left(\mathrm{CH}_{2}\right)$ \\
\hline 1324 & $\ldots$ & not attributed & PMI & $1355 \mathrm{~b}$ & $\delta\left(\mathrm{CH}_{2}\right)$ \\
\hline 1283 & $\ldots$ & not attributed & PMI & $1210 \mathrm{~b}$ & $\nu(\mathrm{CN}-\mathrm{CO})$ \\
\hline 1246 & $\ldots$ & not attributed & PMI & $1094 \mathrm{~b}$ & $\nu(\mathrm{CN}-\mathrm{CO}), \omega(\mathrm{NH})$ \\
\hline 1153 & $\ldots$ & not attributed & PMI & $981 \mathrm{~b}$ & $\rho(\mathrm{CH} / \mathrm{NH})$ \\
\hline 1104 & $\nu(\mathrm{CN})$ & $\mathrm{NH}_{2} \mathrm{COO}^{-} \mathrm{NH}_{4}^{+} / ?$ & PMI & $895 \mathrm{~b}$ & $\rho(\mathrm{CH} / \mathrm{NH})$ \\
\hline 999 & $\nu(\mathrm{CN} / \mathrm{CO})$ & / (rest of $\mathrm{NH}_{2} \mathrm{CH}_{2} \mathrm{OH}$ ?) & $\cdots$ & $\cdots$ & $\cdots$ \\
\hline 829 & $\delta_{\text {oop }}(\mathrm{OCN})$ & $\mathrm{NH}_{2} \mathrm{COO}^{-} \mathrm{NH}_{4}^{+}$ & $\cdots$ & $\cdots$ & $\cdots$ \\
\hline 674 & $\delta\left(\mathrm{COO}^{-}\right)$ & $\mathrm{NH}_{2} \mathrm{COO}^{-} \mathrm{NH}_{4}^{+}$ & $\ldots$ & $\ldots$ & $\cdots$ \\
\hline
\end{tabular}

Notes.

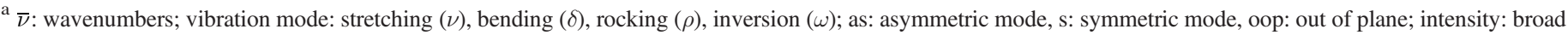
(b) (Bernstein et al. 1994; Bossa et al. 2008; Vinogradoff et al. 2012).

$3376 \mathrm{~cm}^{-1}$; for $\mathrm{CO}_{2}: 7.610^{-17} \mathrm{~cm}$ molecule ${ }^{-1}$ at $2343 \mathrm{~cm}^{-1} ; 5.5$ $10^{-19} \mathrm{~cm} \mathrm{molecule}^{-1}$ at $3600 \mathrm{~cm}^{-1} ; 1.810^{-18} \mathrm{~cm} \mathrm{molecule}^{-1}$ at $3700 \mathrm{~cm}^{-1}$; for $\mathrm{H}_{2} \mathrm{CO}$ : $5.110^{-18} \mathrm{~cm} \mathrm{molecule}^{-1}$ at $1490 \mathrm{~cm}^{-1}$ (Bouilloud et al. 2015), and for $\mathrm{CH}_{2} \mathrm{NH}$ : $3.810^{-18} \mathrm{~cm} \mathrm{molecule}^{-1}$ at $1638 \mathrm{~cm}^{-1} ; 9.610^{-19} \mathrm{~cm}$ molecule ${ }^{-1}$ at $1450 \mathrm{~cm}^{-1}$ (QuintoHernandez et al. 2011).

\section{RESULTS}

\subsection{Ice Analog $1 \mathrm{H}_{2} \mathrm{O}: \mathrm{NH}_{3}: \mathrm{CO}_{2}: \mathrm{H}_{2} \mathrm{CO}$}

Figure 1 shows the thermal evolution of an ice mixture containing $\mathrm{H}_{2} \mathrm{O}: \mathrm{NH}_{3}: \mathrm{CO}_{2}: \mathrm{H}_{2} \mathrm{CO}$ with a 10:1:1:0.3 molecular ratio from 25 to $300 \mathrm{~K}$. The ratios between the molecules have been chosen to be consistent with molecular abundances in the ISM, where water is the most abundant molecule and formaldehyde one of the less abundant molecules (Boogert et al. 2008; Öberg et al. 2011). After formation of the ice mixture, the IR spectrum at $25 \mathrm{~K}$ displays the absorption bands of $\mathrm{H}_{2} \mathrm{O}$ at 3260,1630 , and $830 \mathrm{~cm}^{-1} ; \mathrm{H}_{2} \mathrm{CO}$ at 1722 and $1490 \mathrm{~cm}^{-1}$ (Schutte et al. 1993); $\mathrm{CO}_{2}$ at 2344 and $658 \mathrm{~cm}^{-1}$ (Gerakines et al. 1996); and $\mathrm{NH}_{3}$ at $1113 \mathrm{~cm}^{-1}$ (Kerkhof et al. 1993). However, it appears that a reaction already occurs between the reactants, despite the double injection (see Section 2). The shoulder observed around $1000 \mathrm{~cm}^{-1}$ likely corresponds to the stretching $\mathrm{C}-\mathrm{O} / \mathrm{C}-\mathrm{N}$ mode of the aminomethanol $\mathrm{NH}_{2} \mathrm{CH}_{2} \mathrm{OH}$. Its formation at this temperature was not expected, but the reaction has a low activation barrier in the solid phase, $4.1 \mathrm{~kJ} \mathrm{~mol}^{-1}$ (Bossa et al. 2009).

The ice mixture is then warmed at a rate of $0.5 \mathrm{~K} \mathrm{~min}^{-1}$. At $150 \mathrm{~K}$, many new infrared features are observed in the $1800-1200 \mathrm{~cm}^{-1}$ range. The band at $1000 \mathrm{~cm}^{-1}$ is raising and can clearly be attributed to the aminomethanol. Ammonium carbamate, $\mathrm{NH}_{2} \mathrm{COO}^{-} \mathrm{NH}_{4}^{+}$, from the $\mathrm{CO}_{2}+\mathrm{NH}_{3}$ reaction is also formed (Bossa et al. 2008; Lv et al. 2014; Noble et al. 2014; Rodríguez-Lazcano et al. 2014). The IR spectrum at
$190 \mathrm{~K}$ is recorded after the sublimation of all the remaining reactants, namely, ammonia, formaldehyde, carbon dioxide, and water. The absorption bands of $\mathrm{NH}_{2} \mathrm{COO}^{-} \mathrm{NH}_{4}^{+}$at 1549 , 1400 , and $829 \mathrm{~cm}^{-1}$ (marked by a star) and the band of $\mathrm{NH}_{2} \mathrm{CH}_{2} \mathrm{OH}$ at $1000 \mathrm{~cm}^{-1}$ are now clearly identified in the spectrum. Another product of the $\mathrm{CO}_{2}+\mathrm{NH}_{3}$ reaction, the carbamic acid $\left(\mathrm{NH}_{2} \mathrm{COOH}\right)$ should also be formed after $150 \mathrm{~K}$, from ammonium carbamate as a result of the protic environment of the ice mixture (excess of $\mathrm{H}_{2} \mathrm{O}$ and/or $\mathrm{NH}_{3}$; Noble et al. 2014; Rodríguez-Lazcano et al. 2014). The signature of the $\mathrm{N}-\mathrm{H}$ stretching mode at $3430 \mathrm{~cm}^{-1}$ (marked with a hash in the spectrum at $190 \mathrm{~K}$ ) and the broad band around $1700 \mathrm{~cm}^{-1}$ at $190 \mathrm{~K}$ are characteristic of $\mathrm{NH}_{2} \mathrm{COOH}$ (Bossa et al. 2008). Additionally, at $190 \mathrm{~K}$ some new bands can be observed in the $1700-1200 \mathrm{~cm}^{-1}$ range and are not related to the formation of $\mathrm{NH}_{2} \mathrm{CH}_{2} \mathrm{OH}, \mathrm{NH}_{2} \mathrm{COO}^{-} \mathrm{NH}_{4}^{+}$, or $\mathrm{NH}_{2} \mathrm{COOH}$.

Between 190 and $250 \mathrm{~K}$, the bands related to $\mathrm{NH}_{2} \mathrm{COO}^{-} \mathrm{NH}$ ${ }_{4}^{+}$decrease, as shown by the behavior of the feature observed at $829 \mathrm{~cm}^{-1}$. The new infrared bands, previously observed at $190 \mathrm{~K}$, are now dominant at $250 \mathrm{~K}$, located at 1576, 1458, and $1324 \mathrm{~cm}^{-1}$, while the $2800-3000 \mathrm{~cm}^{-1}$ range presents broad bands, surely containing $\mathrm{NH}_{2} \mathrm{COO}^{-} \mathrm{NH}_{4}^{+}$but also other unknown species. The wavenumbers observed at $250 \mathrm{~K}$ are reported in Table 1 . The band at $999 \mathrm{~cm}^{-1}$ assigned to $\mathrm{NH}_{2} \mathrm{CH}_{2} \mathrm{OH}$ is still observed on the IR spectra at $250 \mathrm{~K}$, while this molecule is meant to sublimate in laboratory conditions around $210-220 \mathrm{~K}$. In this complex ice mixture, we assume that this molecule can be trapped, surrounded by a complex organic matrix, shifting its sublimation at higher temperatures. The broad bands at 1576,1458 , and $1324 \mathrm{~cm}^{-1}$ remain until $290 \mathrm{~K}$ where they are consumed, leading to a residue composed of the characteristic features of HMT and PMI molecules (Figure 1, pointed to by arrows).

For more clarity and details, the spectrum at $300 \mathrm{~K}$ is shown in Figure 2. It is compared to the IR spectra of pure HMT and 


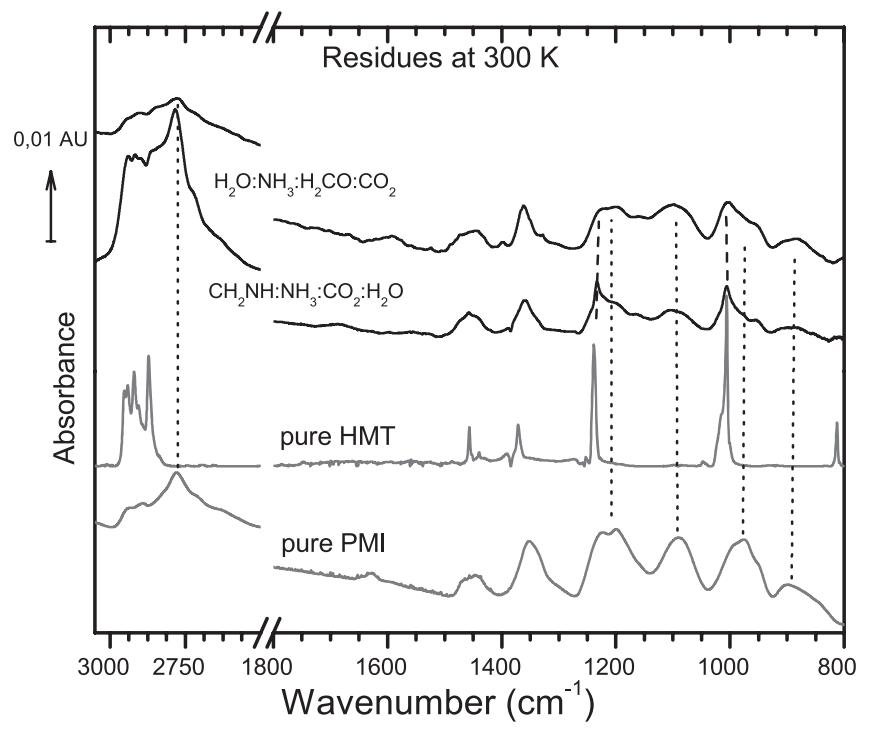

Figure 2. IR spectra of the residue of the ice only warmed $\mathrm{H}_{2} \mathrm{O}: \mathrm{NH}_{3}: \mathrm{CO}_{2}$ : $\mathrm{H}_{2} \mathrm{CO} 10: 1: 1: 0.3$ and $\mathrm{CH}_{2} \mathrm{NH}: \mathrm{NH}_{3}: \mathrm{CO}_{2}: \mathrm{H}_{2} \mathrm{O} 2: 1: 2: 0.2$ at $300 \mathrm{~K}$, compared to the IR spectra of pure HMT and PMI (Vinogradoff et al. 2012).

PMI molecules taken from Vinogradoff et al. (2012). As observed, all the bands are attributed to HMT or to the PMI molecules (Table 1). Nonetheless, we can note that the HMT to PMI abundance ratio is smaller than in the previously published experiments (Vinogradoff et al. 2011, 2012). Since no acid was introduced in the initial ice mixture (i.e., no $\mathrm{HCOOH}$ ) and no photolysis process to form it, another product playing a catalytic role should be formed in situ and counterbalance the lack of formic acid. A part of the unattributed bands observed during the warming could be related to the new intermediate with this catalyst producing HMT and PMI molecules at room temperature. To test this hypothesis, another ice mixture starting from $\mathrm{CH}_{2} \mathrm{NH}$ was studied.

\subsection{Ice Analog $2 \mathrm{CH}_{2} \mathrm{NH}: \mathrm{NH}_{3}: \mathrm{CO}_{2}: \mathrm{H}_{2} \mathrm{O}$}

The methyleneimine, $\mathrm{CH}_{2} \mathrm{NH}$, is a precursor of HMT, coming from the dehydration of $\mathrm{NH}_{2} \mathrm{CH}_{2} \mathrm{OH}$ in our mechanism (Vinogradoff et al. 2012). It has been previously shown that $\mathrm{CH}_{2} \mathrm{NH}$ has to be activated by an acid to polymerize in solid phase and form HMT and PMI in interstellar conditions (Vinogradoff et al. 2012). The specific experiment discussed here presents the reactivity of $\mathrm{CH}_{2} \mathrm{NH}$ with $\mathrm{CO}_{2}$ and $\mathrm{NH}_{3}$.

In Figure 3, the IR spectra of the ice mixture containing $\mathrm{CH}_{2} \mathrm{NH}: \mathrm{NH}_{3}: \mathrm{CO}_{2}: \mathrm{H}_{2} \mathrm{O}$ during warming from $80 \mathrm{~K}$ to room temperature are reported. A very small amount of water is contained in the ice mixture (not quantifiable) to reinforce the matrix environment and restrain the carbon dioxide longer for reaction instead of sublimation, as happened in the ice analog 1 (which is indeed consistent with interstellar ices where water is predominant). To estimate the column density of the other molecules we used the band strengths values from Bouilloud et al. (2015) and Quinto-Hernandez et al. (2011; experimental part). The initial molecular ratio between the major molecules has been estimated to $\mathrm{CH}_{2} \mathrm{NH}: \mathrm{NH}_{3}: \mathrm{CO}_{2}$ $2: 1: 2$, but should be treated with precaution due to the saturation of the $\mathrm{CO}_{2}$ band at $2343 \mathrm{~cm}^{-1}$ (making a

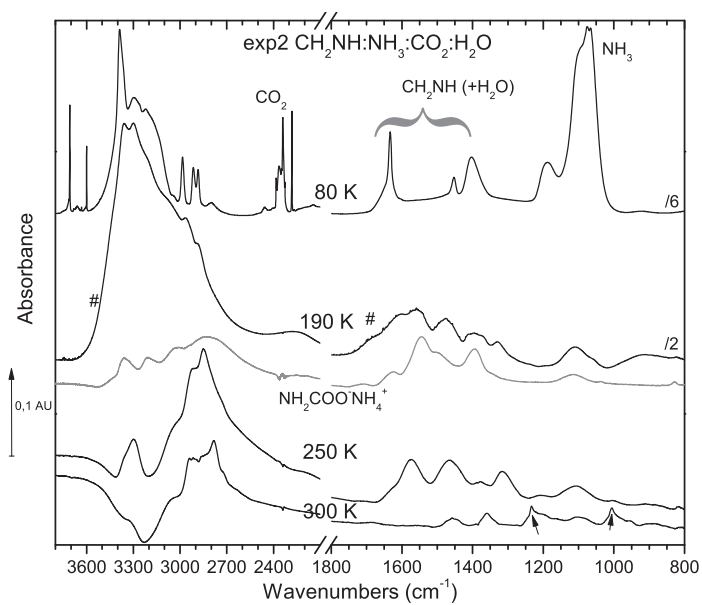

Figure 3. IR spectra of the thermal evolution of the ice $\mathrm{CH}_{2} \mathrm{NH}: \mathrm{NH}_{3}: \mathrm{CO}_{2}: \mathrm{H}_{2} \mathrm{O}$ 2:1:2:0.2 at 80, 190, 250, and $300 \mathrm{~K}$, compared to the IR spectra of $\mathrm{NH}_{2} \mathrm{COO}^{-}$ $\mathrm{NH}_{4}^{+}$at $240 \mathrm{~K}$ (Bossa et al. 2008; hash signs for $\mathrm{NH}_{2} \mathrm{COOH}$ ).

quantification difficult) and also to the use of theoretical band strengths for $\mathrm{CH}_{2} \mathrm{NH}$ compared to the experimental ones. After deposition at $80 \mathrm{~K}$, the characteristics bands of $\mathrm{CO}_{2}$ (Gerakines et al. 1996), $\mathrm{NH}_{3}$ (Kerkhof et al. 1993), and $\mathrm{CH}_{2} \mathrm{NH}$ (Hamada et al. 1984) are observed $\left(\mathrm{H}_{2} \mathrm{O}\right.$ is too low to be observed). No reaction at this stage can be observed. The ice is warmed at $0.5 \mathrm{~K}$ minute $^{-1}$ until $175 \mathrm{~K}$ and then at $4 \mathrm{~K}$ minute ${ }^{-1}$ until $300 \mathrm{~K}$.

At $190 \mathrm{~K}$, the IR spectrum exhibits bands relatives to $\mathrm{NH}_{2} \mathrm{COO}^{-} \mathrm{NH}_{4}^{+}$, and likely some $\mathrm{NH}_{2} \mathrm{COOH}$, due to the multiple shoulders observed around $1700 \mathrm{~cm}^{-1}$ (hash signs). At $250 \mathrm{~K}$, in addition to the three broad bands already observed in the previous experiment around 1580,1460, and $1310 \mathrm{~cm}^{-1}$, new absorption bands are observed at $3295 \mathrm{~cm}^{-1}$ in the $\mathrm{N}-\mathrm{H}$ stretching mode region at 2923 and $2853 \mathrm{~cm}^{-1}$ in the $\mathrm{C}-\mathrm{H}$ stretching mode region. All these unknown bands could correspond to a last intermediate since at $290 \mathrm{~K}$ they decrease, while the characteristics bands of HMT and PMI arise (Figure 3).

The IR spectrum of the residues of the two experiments is reported in Figure 2 for comparison with the pure IR spectra of HMT and PMI. The relative abundance between HMT and PMI are different in the two residues, and the HMT/PMI ratio is still lower than in our previous studies (Vinogradoff et al. 2011, 2012).

\section{DISCUSSION}

\subsection{Pathways for the HMT and PMI formation from $\mathrm{NH}_{3}: \mathrm{H}_{2} \mathrm{CO}: \mathrm{CO}_{2}$ in Water Environment}

HMT and PMI formation from formaldehyde and ammonia in interstellar ice analogs requires an acid as a catalyst. In the two ice analogs studied here, unlike previous studies by Vinogradoff et al. (2012), no acid was initially introduced. Then, the only way to form HMT and PMI is to produce an acid in situ during the thermal activation, likely the carbamic acid. We hypothesized that the $\mathrm{NH}_{2} \mathrm{COOH}$ could play the same role as $\mathrm{HCOOH}$. In this case and by analogy of Vinogradoff et al. (2012) with $\mathrm{HCOOH}$, the unknown IR absorption bands observed from 190 to $290 \mathrm{~K}$ (located at 1573, 1463, and $1318 \mathrm{~cm}^{-1}$; Figures 1 and 3 ) could be related to a salt of 
$\mathrm{NH}_{2} \mathrm{COO}^{-}$with a precursor of HMT and PMI. The proposed mechanism is reported in Equation (2) ( $\Delta$ :heating). For the first time, out of the simple three-molecule mixture, $\mathrm{NH}_{3}: \mathrm{H}_{2} \mathrm{CO}$ : $\mathrm{CO}_{2}$, we show that HMT and PMI can be formed without any photolysis and without acid in the initial mixture.

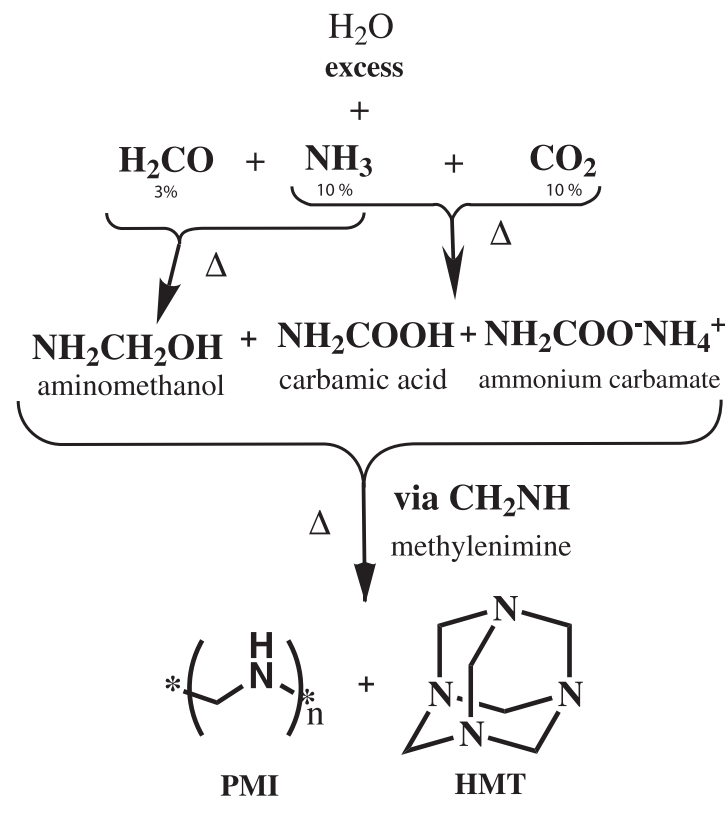

major product

A significant difference is, however, observed with $\mathrm{NH}_{2} \mathrm{COOH}$ as the catalyst of reactions, which results in the increase of PMI production compared to HMT. Indeed, based on the band intensities of HMT and PMI (Figure 2) and from our previous study about HMT formation (Vinogradoff et al. 2012), we can roughly approximate that the production of HMT is divided by 10 with $\mathrm{NH}_{2} \mathrm{COOH}$ as the catalyst, while the production of PMI seems to be only divided by 2 . The chemical property of the catalyst, such as its acidity, could have a strong influence on the mechanism, promoting the PMI formation (polymerization of $\mathrm{CH}_{2} \mathrm{NH}$ ) instead of the cyclization to HMT (Vinogradoff et al. 2012). The influence of the ammonium carbamate on the polymerization reaction is not obvious but could also have a role for the stabilization of the monomer $\mathrm{CH}_{2} \mathrm{NH}$. The PMI polymer has interesting properties since it sublimes at higher temperatures than HMT (up to $550 \mathrm{~K}$ in our experimental conditions compared to $400 \mathrm{~K}$ for HMT; Vinogradoff et al. 2012) and presents the same bonds as HMT $(\mathrm{C}-\mathrm{N})$.

This study reveals that HMT and PMI can be formed without $\mathrm{HCOOH}$, as determined in our previous studies (Equation (1)). The catalytic role of $\mathrm{HCOOH}$ is bypassed by the thermal production of the carbamic acid $\mathrm{NH}_{2} \mathrm{COOH}$, coming from the $\mathrm{CO}_{2}$ and $\mathrm{NH}_{3}$ reaction in the solid phase. Thus, our study confirms the importance of acid species (i.e., $\mathrm{HCOOH}$ or $\mathrm{NH}_{2} \mathrm{COOH}$ ) for the formation of HMT and PMI from formaldehyde and ammonia in interstellar ice analogs.

\subsection{Astrochemical/Astrophysical Implications}

Laboratory experiments are useful for predicting the possible chemical evolution of ices during stellar and planetary formation. Icy matter in our solar system might have passed through the same kind of evolution during its early stages, and the resulting solid matter could be part of the comets' or asteroids' pristine composition.

Astronomical observations toward protostar environment reveal the presence of numerous ices with a high abundance of $\mathrm{CO}_{2}$, up to $30 \%$ in regard to $\mathrm{H}_{2} \mathrm{O}$ (Boogert et al. 2008; Öberg et al. 2011). Ammonia (up to 8\%), formaldehyde (up to 6\%), and formic acid (1\%-5\%; regarding water) are also among the most abundant molecules detected in the solid phase around protostars. Since $\mathrm{CO}_{2}$ is more abundant in interstellar ices than $\mathrm{HCOOH}$, the new mechanism to form HMT and PMI involving $\mathrm{NH}_{2} \mathrm{COOH}$ (Equation (2)) could be more representative and also should be considered in the chemical reaction models occurring in interstellar grains.

Considering an aggregate of icy interstellar grains formed in the inner part of protoplanetary disk and submitted to vertical and radial mixing (Caselli \& Ceccarelli 2012 and references therein), we represent in Figure 4 the chemical evolution of the abundant molecules considered here $\mathrm{H}_{2} \mathrm{O}$, $\mathrm{CO}_{2}, \mathrm{NH}_{3}$, and $\mathrm{H}_{2} \mathrm{CO}$, widespread at the surface and inside the larger grain.

During stellar formation, and depending on its position in the disk, this grain can be submitted to UV light and warmed enough to reach $200 \mathrm{~K}$ (in this scenario, cosmic rays are neglected). The UV light affecting more of the surface (up to hundreds of nanometers deep) than the interior, ammonia/ formaldehyde/carbon dioxide will be submitted to photolysis leading to new compounds and other reactants. On the other hand, the molecules contained in the core will be protected (from UV light and desorption) and submitted only to thermal effects. In this scenario and according to our results, with an increased temperature, HMT and PMI could be produced more efficiently in the mantle, but should also be produced at the surface (Vinogradoff et al. 2013). Indeed, depending on the ratio of mantle to interior, not reached by UV photons, a larger number of synthesized molecules can be present in the interior. Moreover, whatever the composition of the initial ice analog and the processes affecting the ice, HMT and PMI are very often detected at $300 \mathrm{~K}$ in the organic residue (Bernstein et al. 1995; Cottin et al. 2001; Muñoz Caro \& Schutte 2003; Muñoz Caro et al. 2004; Vinogradoff et al. 2013).

Thus, both molecules have to be searched for directly in astrophysical objects such as comets, IDPs, or even primitive carbonaceous chondrites that have not undergone secondary processes (i.e., hydrothermalism or metamorphism; Remusat 2015). Indeed, the observations of interstellar ices from cores to protosolar environments show a correlation in the abundance variations of $\mathrm{C}, \mathrm{N}$, and $\mathrm{O}$ depending on the environment history but also a comparable spread in abundance with comet molecules of our solar system (Öberg et al. 2011; Caselli \& Ceccarelli 2012). This suggests a survival of some chemical material from the ISM to the protoplanetary disk and therefore in planetary objects such as comet or meteorites.

Currently, the most promising analyses are the ones conducted by the Rosetta mission, which is operating in situ analyses in the environment of comet 67P/ChuryumovGerasimenko. At the nucleus's surface, chemical analyses can be performed thanks to the COSAC and PTOLEMY instruments (gas chromatographs coupled with mass spectrometers) on board the Philae lander (Cottin et al. 2001; Wright et al. 2007; Goesmann et al. 2014). In the cometary environment, mass spectrometry seems to be the most suitable technique to detect complex organic molecules either in a gas or solid phase 


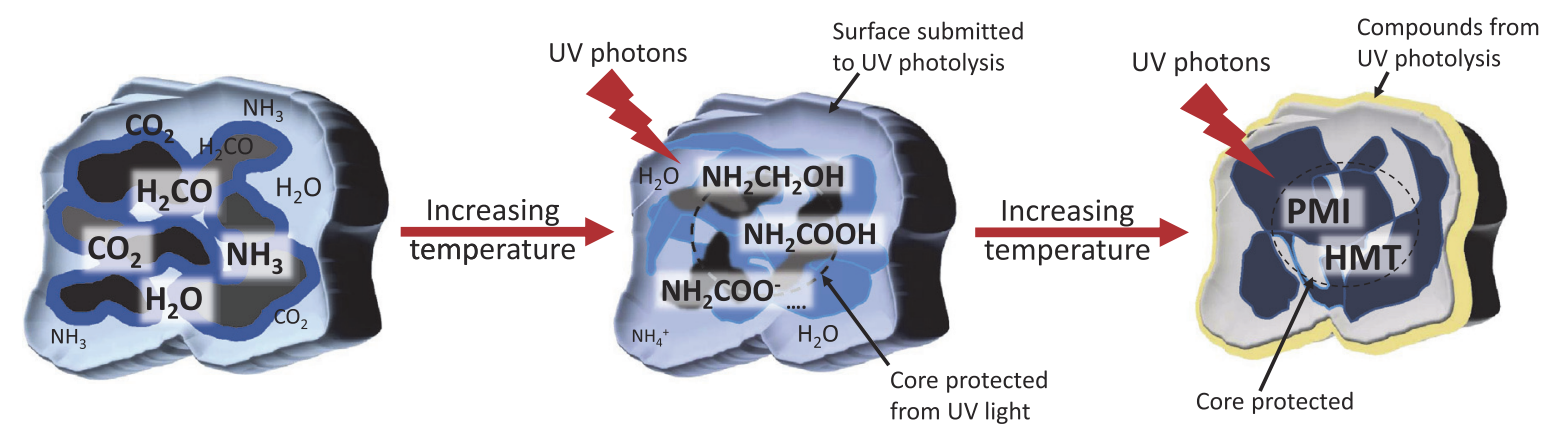

Figure 4. Schematic view of an icy grain aggregate, submitted to UV light and heating effects, to represent the thermal chemical evolution of $\mathrm{H}_{2} \mathrm{O}, \mathrm{CO}_{2}$, $\mathrm{NH}_{3}$, and $\mathrm{H}_{2} \mathrm{CO}$ in the core mantle during evolution of grains in the protoplanetary disk.

thank to the ROSINA and COSIMA instruments (Balsiger et al. 2007; Kissel et al. 2007). Concerning COSIMA, some calibrations have already been performed for HMT (Le Roy et al. 2015), and it could be interesting to conduct further similar studies on the PMI molecule. The search for these molecules could be used as a probe to estimate the thermal history of the grain incorporated in the cometary nuclei during their formation.

\section{CONCLUSION}

Thermal reactions can lead to complex organic molecules with cyclic or polymer structures. Various chemical pathways need to be considered one by one and together to increase our understanding of the thermal chemistry in ices. In this study, we investigated ice mixtures containing $\mathrm{H}_{2} \mathrm{O}: \mathrm{NH}_{3}: \mathrm{H}_{2} \mathrm{CO}: \mathrm{CO}_{2}$ and $\mathrm{CH}_{2} \mathrm{NH}: \mathrm{NH}_{3}: \mathrm{CO}_{2}: \mathrm{H}_{2} \mathrm{O}$ simply warmed from 20 to $300 \mathrm{~K}$. At room temperature $(300 \mathrm{~K})$, an organic residue containing HMT and PMI is obtained. We propose the carbamic acid $\mathrm{NH}_{2} \mathrm{COOH}$, a product of the thermal reaction between $\mathrm{CO}_{2}$ and $\mathrm{NH}_{3}$, can act as a catalyst of the reactions, enabling the formation of HMT and PMI. Thanks to carbon dioxide, we provide evidence that HMT, and more likely PMI, can be formed within the ice mantle only by thermal activation, regardless of the amount of available UV light or the presence of $\mathrm{HCOOH}$ supposed to be a key molecule in our previous studies.

These studies have interesting implications regarding the presence of HMT and PMI in the ISM or in cometary environments, and both molecules have to be searched for in different astrophysical objects, such as comets by the Rosetta mission. Overall, studies about HMT and PMI molecules, as source of $-\mathrm{C}-\mathrm{N}$ bond likely formed in interstellar grains, are relevant for complex organic chemistry in a planetary system.

This work has been supported by CNES (Centre National d'Etudes Spatiales, French space agency) in the frame of the EXPOSE International Space Station and COSIMA programs, by UPEC (Université Paris-Est Créteil), by the Programme National de Planétology (PNP-CNRS), DIM ACAV (Astrophysique et Conditions d'Apparition de la Vie), PCMI (Physique Chimie du Milieu interstellaire), and the EPOV CNRS program (Environnements Planétaires et Origines de la Vie). We would also like to thank the ESEP Labex. V.V. had an associate professor grant from UPEC during the period experiments were conducted.

\section{REFERENCES}

Balsiger, H., Altwegg, K., Bochsler, P., et al. 2007, SSRv, 128, 745

Bennett, C. J., Hama, T., Kim, Y. S., Kawasaki, M., \& Kaiser, R. I. 2011, ApJ, 727, 27

Bernstein, M. P., Sandford, S. A., Allamandola, L. J., \& Chang, S. 1994, JPhCh, 98, 12206

Bernstein, M. P., Sandford, S. A., Allamandola, L. J., Chang, S., \& Scharberg, M. A. 1995, ApJ, 454, 327

Boogert, A. C. A., Pontoppidan, K. M., Knez, C., et al. 2008, ApJ, 678, 985

Bossa, J. B., Theulé, P., Duvernay, F., Borget, F., \& Chiavassa, T. 2008, A\&A, 492, 719

Bossa, J. B., Theule, P., Duvernay, F., \& Chiavassa, T. 2009, ApJ, 707, 1524

Bouilloud, M., Fray, N., Bénilan, Y., et al. 2015, MNRAS, 451, 2145

Caselli, P., \& Ceccarelli, C. 2012, A\&ARv, 20, 56

Cottin, H., Szopa, C., \& Moore, M. H. 2001, ApJ, 561, 139

Danger, G., Borget, F., Chomat, M., et al. 2011, A\&A, 535, A47

Danger, G., Orthous-Daunay, F. R., de Marcellus, P., et al. 2013, GeCoA, 118,184

Duvernay, F., Danger, G., Theulé, P., Chiavassa, T., \& Rimola, A. 2014, ApJ, 791,75

Gerakines, P. A., Schutte, W. A., \& Ehrenfreund, P. 1996, A\&A, 312, 289

Gibb, E. L., Whittet, D. C. B., Boogert, A. C. A., \& Tielens, A. 2004, ApJS, 151,35

Goesmann, F., Raulin, F., Bredehöft, J. H., et al. 2014, P\&SS, 103, 308

Gould, R. J., Gold, T., \& Salpeter, E. E. 1963, ApJ, 138, 408

Guillemin, J. C., \& Denis, J. M. 1988, Tetrahedron, 44, 4431

Hamada, Y., Hashiguchi, K., Tsuboi, M., Koga, Y., \& Kondo, S. 1984, JMoSp, 105,70

Herbst, E., \& Van Dishoeck, E. F. 2009, ARA\&A, 47, 427

Kerkhof, O., Schutte, W. A., \& Ehrenfreund, P. 1993, A\&A, 346, 994

Kissel, J., Altwegg, K., Clark, B. C., et al. 2007, SSRv, 128, 823

Le Roy, L., Bardyn, A., Briois, C., et al. 2015, P\&SS, 105, 1

Lv, X. Y., Boduch, P., Ding, J. J., et al. 2014, PCCP, 16, 3433

Muñoz Caro, G. M., Meierhenrich, U., Schutte, W. A., Thiemann, W. H. P., \& Greenberg, J. M. 2004, A\&A, 413, 209

Muñoz Caro, G. M., \& Schutte, W. A. 2003, A\&A, 412, 121

Noble, J. A., Theule, P., Duvernay, F., et al. 2014, PCCP, 16, 23604

Öberg, K. I., Boogert, A. C. A., Pontoppidan, K. M., et al. 2011, ApJ, 740, 109

Öberg, K. I., Garrod, R. T., van Dishoeck, E. F., \& Linnartz, H. 2009, A\&A, 504,891

Quinto-Hernandez, A., Wodtke, A. M., Bennett, C. J., Kim, Y. S., \& Kaiser, R. I. 2011, JPCA, 115, 250

Remusat, L. 2015, in Planetary Mineralogy, Vol. 15, ed. M. R. Lee \& H. Leroux (Chantilly, VA: Mineralogical Society of America), chap. 2

Rodríguez-Lazcano, Y., Maté, B., Herrero, V. J., Escribano, R., \& Gálvez, Ó 2014, PCCP, 16, 3371

Schutte, W. A., Allamandola, L. J., \& Sandford, S. A. 1993, Icar, 104, 118

Theulé, P., Duvernay, F., Danger, G., et al. 2013, AdSpR, 52, 1567

Vinogradoff, V., Duvernay, F., Danger, G., Theulé, P., \& Chiavassa, T. 2011, A\&A, 530, 128

Vinogradoff, V., Fray, N., Duvernay, F., et al. 2013, A\&A, 551, 128

Vinogradoff, V., Rimola, A., Duvernay, F., et al. 2012, PCCP, 14, 12309

Wolman, Y., Miller, S. L., Ibaez, J., \& Oró, J. 1971, Sci, 174, 1038

Wright, I. P., Barber, S. J., Morgan, G. H., et al. 2007, SSRv, 128, 363 